\section{(2) \\ BRAZILIAN JOURNAL \\ OF MEDICAL AND BIOLOGICAL RESEARCH}

www.bjournal.com.br
ISSN 1414-431X

Volume 45 (11) 995-1101 November 2012

BIOMIEDICAL SCIENCES

AND

CLINICAL INVESTIGATION

Braz J Med Biol Res, November 2012, Volume 45(11) 1080-1085

doi: 10.1590/S0100-879X2012007500131

\title{
Association of sulfur dioxide exposure with circulatory system deaths in a medium-sized city in Brazil
}

C.T. Amancio and L.F.C. Nascimento

The Brazilian Journal of Medical and Biological Research is partially financed by

\section{Q QNPPq}

Ministério da Ciência e Tecnologia

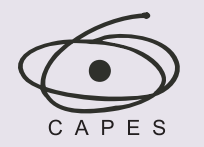

Ministério da Educação

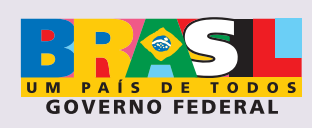

DTFAPESP
Institutional Sponsors

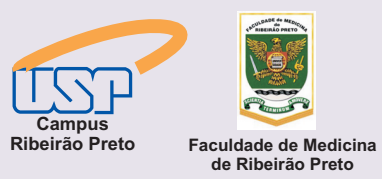

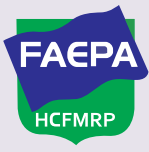

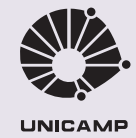

UNICAMP
Ф SHIMADZU

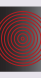

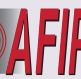

Associas, Associaçáa
Fundo
de Incentivo delincentivo
aेesquisa

Explore High - Performance MS Orbitrap Technology andilicica Thermo 


\title{
Association of sulfur dioxide exposure with circulatory system deaths in a medium-sized city in Brazil
}

\author{
C.T. Amancio ${ }^{1}$ and L.F.C. Nascimento ${ }^{1,2}$ \\ ${ }^{1}$ Departamento de Medicina, Universidade de Taubaté, Taubaté, SP, Brasil \\ 2Programa de Pós-Graduação em Ciências Ambientais, Universidade de Taubaté, Taubaté, SP, Brasil
}

\begin{abstract}
There is a demonstrable association between exposure to air pollutants and deaths due to cardiovascular diseases. The objective of this study was to estimate the effects of exposure to sulfur dioxide on mortality due to circulatory diseases in individuals 50 years of age or older residing in São José dos Campos, SP. This was a time-series ecological study for the years 2003 to 2007 using information on deaths due to circulatory disease obtained from Datasus reports. Data on daily levels of pollutants, particulate matter, sulfur dioxide $\left(\mathrm{SO}_{2}\right)$, ozone, temperature, and humidity were obtained from the São Paulo State Environmental Agency. Moving average models for 2 to 7 days were calculated by Poisson regression using the R software. Exposure to $\mathrm{SO}_{2}$ was analyzed using a unipollutant, bipollutant or multipollutant model adjusted for mean temperature and humidity. The relative risks with $95 \% \mathrm{Cl}$ were obtained and the percent decrease in risk was calculated. There were 1928 deaths with a daily mean ( $\pm \mathrm{SD}$ ) of $1.05 \pm 1.03$ (range: $0-6$ ). Exposure to $\mathrm{SO}_{2}$ was significantly associated with mortality due to circulatory disease: $\mathrm{RR}=1.04(95 \% \mathrm{Cl}=1.01$ to 1.06$)$ in the 7-day moving average, after adjusting for ozone. There was an $8.5 \%$ decrease in risk in the multipollutant model, proportional to a decrease of $\mathrm{SO}_{2}$ concentrations. The results of this study suggest that residents of medium-sized Brazilian cities with characteristics similar to those of São José dos Campos probably have health problems due to exposure to air pollutants.
\end{abstract}

Key words: Air pollution; Sulfur dioxide; Cardiovascular diseases; Mortality; Air pollutants; Stroke

\section{Introduction}

Circulatory diseases are the leading cause of death in Brazil and are responsible for remarkable financial and social costs, as observed in the State of São Paulo, where $\mathrm{R} \$ 500$ million (US\$1 = R $\$ 1.70$ ) were spent in hospitalization of individuals aged 50 years or more in 2010 due to these causes (1). Numerous risk factors for circulatory diseases have been well elucidated, such as age, diabetes, dyslipidemia, smoking, alcoholism and, more recently, exposure to environmental factors such as air pollution $(2,3)$.

Environmental pollution is an important topic today because it is a preventable public health problem. Its principal sources of emissions are the industries and combustion motor vehicles and the main air pollutants are particulate matter $\left(\mathrm{PM}_{10}\right)$, sulfur dioxide $\left(\mathrm{SO}_{2}\right)$, ozone $\left(\mathrm{O}_{3}\right)$, carbon monoxide (CO), and nitrogen oxides (NOx) (4). It has been shown that, even when within acceptable standards according to environmental legislation, exposure to pollutants is a risk factor for both cardiovascular and respiratory morbidity and mortality (5-8).

It is known that the impact of pollutants on vascular diseases is greater among adult and the elderly, while respiratory diseases are more common among children and the elderly (9).

Moreover, the adverse effects of exposure to air pollutants occur both in populations living in large cities and in medium-sized cities (10-12).

Study areas in São Paulo have shown an association between exposure and hospital admissions for acute myocardial infarction, showing a stronger association with $\mathrm{SO}_{2}$ (10). A European study (APHEA-II) suggested that $\mathrm{SO}_{2}$ can have an independent role in triggering cardiovascular events and hospitalizations due to these causes, coinciding significantly with increases in daily levels of $\mathrm{SO}_{2}$ on the same day and on the day before exposure (13). 
Are the effects of exposure to $\mathrm{SO}_{2}$ the same in mediumsized cities? Faced with this challenge, the aim of this study was to estimate these effects on mortality due to circulatory disease in São José dos Campos, SP, Brazil.

\section{Material and Methods}

This was an ecological time-series study in which information on deaths from circulatory disease was obtained for individuals 50 years of age or older. The study was conducted in São José dos Campos, a medium-sized city located $80 \mathrm{~km}$ from São Paulo, between two mountain ranges, with a population of about 700,000 inhabitants. The city is located at latitude $23^{\circ} 11^{\prime} \mathrm{S}$ and longitude $45^{\circ}$ $53^{\prime}$ ' $\mathrm{W}$ and its altitude is $600 \mathrm{~m}$ above sea level. It has about 1100 industrial establishments with emphasis on automobile manufacturing, aerospace and pharmaceutical industries, and oil refinery. The city is crossed by the Dutra Highway, which is the most important highway in Brazil with heavy car, truck and bus traffic involving about 130,000 vehicles per day (14).

Data about the selected circulatory diseases culminating in death were obtained from the Brazilian Mortality Information System (SIM). According to the International Classification of Diseases, 10th revision, they were coded as ICD-10 = I10, I11, I15, and I20 to I25 (heart diseases), and 160 to 167 (stroke). The study considered the data for the period from January 1, 2003 to December 31, 2007.

We obtained data about the daily levels of air pollutants such as $\mathrm{SO}_{2}, \mathrm{PM}_{10}$ and $\mathrm{O}_{3}$ from the São Paulo State Environmental Agency (CETESB), which has a monitoring station in the central region of São José dos Campos located $2 \mathrm{~km}$ north of the Dutra Highway. Data collection about the levels of pollutants was started at the first hour of the day and continued for $24 \mathrm{~h}$. All data were quantified in $\mu \mathrm{g} / \mathrm{m}^{3}$, considering the daily average for $\mathrm{SO}_{2}$ and $\mathrm{PM}_{10}$ and a maximum of $1 \mathrm{~h}$ of the day for $\mathrm{O}_{3}$.

In São José dos Campos, the $\mathrm{PM}_{10}$ pollutant is composed of nitrate, sulfate and chloride anions and constituent particles of soil and soot; sulfate was predominantly found in the fine fraction $\left(\mathrm{PM}_{\leq 2.5}\right)$, the lowest values were detected for percent chloride ion, which was the predominant coarse fraction $\left(\mathrm{PM}_{2.5-10}\right)$; for nitrate, the largest percentages were found in the coarse fraction $\left(\mathrm{PM}_{2.5-10}\right)$, approximately two times higher than those found in the $\mathrm{PM}_{\leq 2.5}$ (15).

Temperature and relative humidity data were obtained from the Foundation for Science, Technology and Space Applications (FUNCATE).

The dependent variable was death due to circulatory diseases; the independent variable was sulfur dioxide, adjusted for $\mathrm{PM}_{10}, \mathrm{O}_{3}$, mean temperature and humidity.

Since the manifestations of exposure to pollutants are believed to present a lag effect, i.e., that an individual exposed to pollution today may present health problem on the same day or some days later, models with moving average ranging from 2 to 7 days after exposure to the air pollutant were constructed. The moving average, in turn, is a tool used to obtain the cumulative effect of concentrations of pollutants and is more consistent with reality. Studies do not show consensus about the days included in the moving average (16).

\section{Statistical analysis}

Time-series analysis was used, with the unit of observation being the day and not the individual. The analysis assessed the fraction of the daily variations in death counts that was explained by the daily variations in air pollution, $\mathrm{SO}_{2}$ in particular, of the preceding days, after controlling for the other variables that varied in time. We used generalized linear models of Poisson regression to estimate the association between exposure to $\mathrm{SO}_{2}$ and deaths due to circulatory system conditions in persons aged 50 years or more, using the R software (R Systems International, India). We chose this statistic approach because the unit of study, death due to circulatory disease, is a counting event.

The analysis was based on a unipollutant model for $\mathrm{SO}_{2}$ adjusted for average temperature and humidity. Bipollutant models were constructed, a model with $\mathrm{SO}_{2}$ and $\mathrm{PM}_{10}$ and the other with $\mathrm{SO}_{2}$ and $\mathrm{O}_{3}$. The multipollutant model included $\mathrm{SO}_{2}$, particulate matter and ozone adjusted for temperature and humidity. Relative risks (RR) were estimated for diseases of the circulatory system, for heart disease and stroke.

Thus, we obtained the coefficients (coeff) and its standard deviations (SD) that permitted the calculation of RR and 95\% confidence intervals $(95 \% \mathrm{Cl})$, through the formulas: $\mathrm{RR}=\exp ($ coeff) and $95 \% \mathrm{Cl}=\exp [$ coeff $\pm 1.96(\mathrm{SD})]$.

We report descriptive analysis of all study variables and correlations among them through Pearson's correlation coefficients, for which we used the computer program SPSS version 15.0. The decrease in risk of death for the interquartile difference for $\mathrm{SO}_{2}$ was estimated using the formula: $P D=[\exp (-$ coeff * VIQPOL) - 1] * 100 , where PD is the percent decrease in the risk of circulatory deaths and VIQPOL is the difference between the values of the first and third quartiles of the concentration of this pollutant. PD was estimated only for $\mathrm{SO}_{2}$, considering the difference between the values of the first and third quartiles of the concentration of this pollutant obtained by the multipollutant model for circulatory diseases. The level of significance was set at $5 \%$ for all tests.

\section{Results}

A total of 10,111 deaths of individuals aged 50 years or more occurred during the study period from January 1, 2003 to December 31, 2007; 1928 of these deaths (19.1\%) were due to circulatory diseases. There were 1021 (53.0\%) deaths due to cardiovascular diseases and 907 (47.0\%) deaths due to stroke. The descriptive analysis of the variables under study is given in Table 1. The average particulate matter was 
Table 1. Daily mean values of the variables studied in São José dos Campos, Brazil, 2003-2007.

\begin{tabular}{lrcc}
\hline & Mean $\pm \mathrm{SD}$ & Minimum & Maximum \\
\hline Deaths & $1.06 \pm 1.03$ & 0 & 6 \\
$\mathrm{PM}_{10}\left(\mu \mathrm{g} / \mathrm{m}^{3}\right)$ & $26.97 \pm 14.8$ & 4 & 100 \\
$\mathrm{SO}_{2}\left(\mu \mathrm{g} / \mathrm{m}^{3}\right)$ & $4.38 \pm 3.52$ & 1 & 34 \\
$\mathrm{O}_{3}\left(\mu \mathrm{g} / \mathrm{m}^{3}\right)$ & $80.00 \pm 33.3$ & 5 & 232 \\
Temperature $\left({ }^{\circ} \mathrm{C}\right)$ & $21.73 \pm 3.84$ & 12.7 & 36.2 \\
Humidity $(\%)$ & $76.24 \pm 15.0$ & 33 & 100.0 \\
\hline
\end{tabular}

$\mathrm{PM}_{10}=$ particulate matter

$26.9 \pm 14.8 \mu \mathrm{g} / \mathrm{m}^{3}$, not exceeding the established pattern of $50 \mu \mathrm{g} / \mathrm{m}^{3}$ annual average or the average annual daily average of $150 \mu \mathrm{g} / \mathrm{m}^{3}$. Annual average daily level of $\mathrm{SO}_{2}$ was $4.4 \pm 3.5 \mu \mathrm{g} / \mathrm{m}^{3}$ and a maximum of $1 \mathrm{~h}$ of the day for $\mathrm{O}_{3}$ was $232 \pm 33.3 \mu \mathrm{g} / \mathrm{m}^{3}$, with acceptable values for the two pollutants having been established up to 80 and 160 $\mu \mathrm{g} / \mathrm{m}^{3}$, respectively. This shows that $\mathrm{SO}_{2}$ did not exceed the acceptable value, whereas $\mathrm{O}_{3}$ exceeded this limit on 34 occasions for a total of 1826 days of study.

The year-by-year variation during the study period is shown in Figure 1. There was a high seasonal behavior for $\mathrm{PM}$ and $\mathrm{SO}_{2}$, but not for $\mathrm{O}_{3}$.

The mortality rate from all circulatory diseases varied little in terms of total annual number, with the lowest number occurring in 2005 (366 deaths) and the largest in 2007 (401 deaths). However, when the rate was analyzed on a monthly basis there was seasonal variation, with larger numbers in the colder months of the year and lower numbers in warmer months.

Table 2 presents the correlation matrix between the variables of the study. We observed positive correlations between pollutants, whereas deaths due to circulatory diseases showed a positive correlation with $\mathrm{PM}_{10}$ and $\mathrm{SO}_{2}$, and a negative correlation with $\mathrm{O}_{3}$. The weather variables showed negative correlations with deaths and air pollution, except for temperature, which was positively correlated with $\mathrm{PM}_{10}$ and $\mathrm{O}_{3}$.

A generalized linear model using Poisson regression analysis was used to determine the association between exposure to $\mathrm{SO}_{2}$ and deaths due to circulatory diseases and is expressed as RR (Figure 2A-D). The model presents the $\mathrm{RR}$ and their $95 \% \mathrm{Cl}$ for $\mathrm{SO}_{2}$ in the unipollutant model, in the bipollutant model and in the multipollutant model with PM and $\mathrm{O}_{3}$, adjusted for mean temperature and humidity. The $\mathrm{RR}$ for death due to circulatory diseases, heart diseases and stroke are shown in Table 3; it is possible to note the contribution of death due to stroke to mortality due to circulatory diseases. The maximum RR obtained was 1.04 $(95 \% \mathrm{Cl}=1.01$ to 1.06$)$ for the bipollutant model adjusted for $\mathrm{O}_{3}$. There was a decreased risk of death of approximately $8.5 \%$ for the fifth, sixth, and seventh moving average, in the multipollutant model for a decrease in the interquartile
Table 2. Pearson's correlation matrix between all atmospheric variables. São José dos Campos, Brazil, 2003-2007.

\begin{tabular}{lcccccc}
\hline & Deaths & $\mathrm{PM}_{10}$ & $\mathrm{SO}_{2}$ & $\mathrm{O}_{3}$ & Temperature & Humidity \\
\hline Deaths & 1 & $0.05^{*}$ & $0.06^{*}$ & -0.02 & -0.04 & -0.01 \\
$\mathrm{PM}_{10}$ & & 1 & $0.51^{*}$ & $0.39^{*}$ & $0.16^{*}$ & $-0.37^{*}$ \\
$\mathrm{SO}_{2}$ & & & 1 & $0.26^{*}$ & -0.03 & $-0.30^{*}$ \\
$\mathrm{O}_{3}$ & & & & 1 & $0.04^{*}$ & $-0.35^{*}$ \\
Temperature & & & & & 1 & $-0.68^{*}$ \\
Humidity & & & & & & 1 \\
\hline
\end{tabular}

$\mathrm{PM}_{10}=$ particulate matter. ${ }^{*} \mathrm{P}<0.05$.
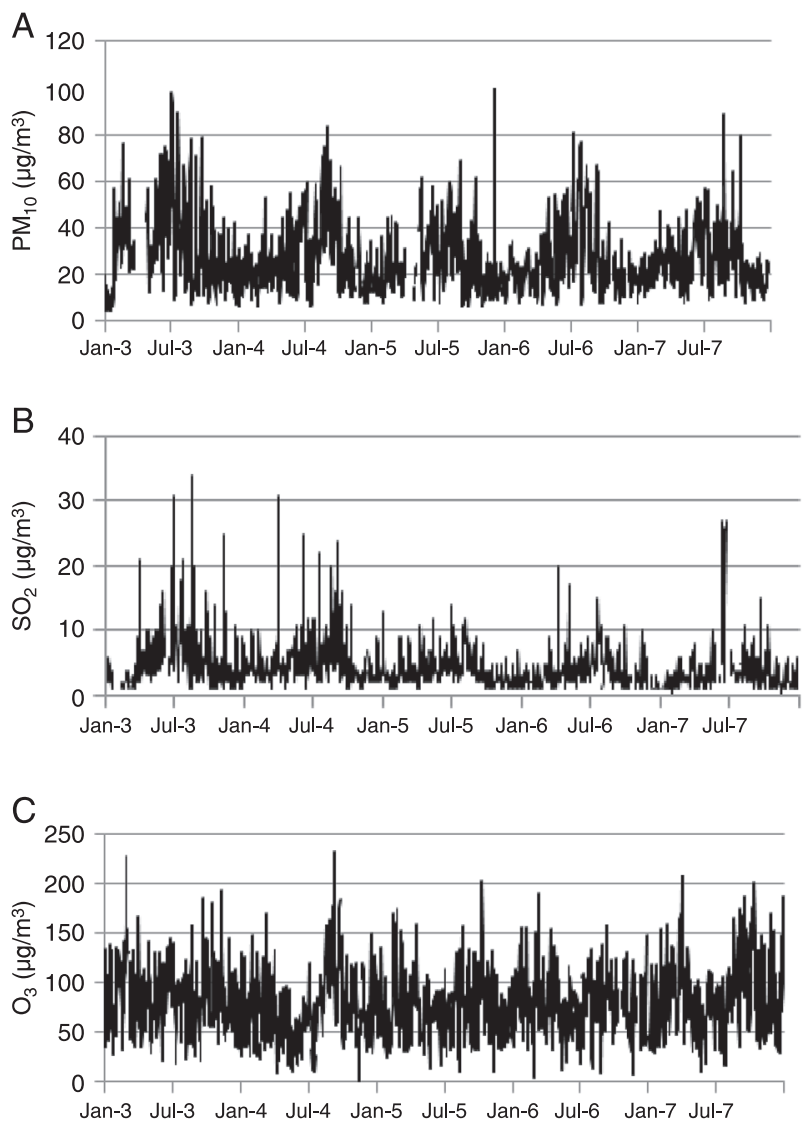

Figure 1. Daily pollutant concentration during the study period. São José dos Campos, Brazil, 2003-2007. A, $\mathrm{PM}_{10} ; B, \mathrm{SO}_{2} ; C, \mathrm{O}_{3}$.

difference $\left(3 \mu \mathrm{g} / \mathrm{m}^{3}\right)$ of $\mathrm{SO}_{2}$ (Figure $\left.2 \mathrm{E}\right)$.

\section{Discussion}

This is the first time-series study reported to estimate the association between exposure to air pollutants and circulatory deaths in a medium-size city in Brazil.

This was an ecological study, since the unit of study was the population and not the individual. The choice of statistical analysis using a generalized linear model rather 

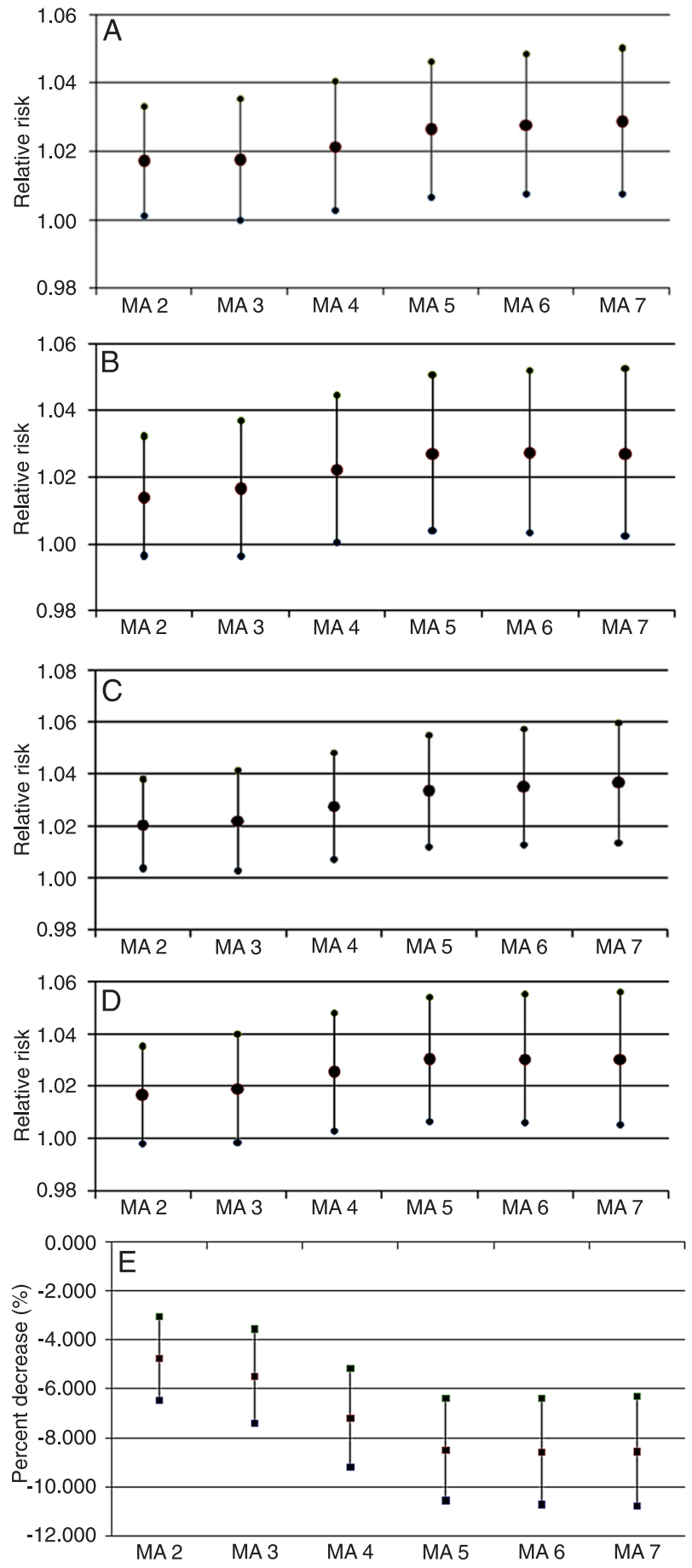

Figure 2. Relative risks and $95 \%$ confidence interval for deaths due to cardiovascular circulatory diseases by exposure to sulfur dioxide: $A$, unipollutant model; $B$, bipollutant model adjusted for $\mathrm{PM}_{10} ; C$, bipollutant model adjusted for $\mathrm{O}_{3} ; D$, multipollutant model adjusted for $\mathrm{PM}_{10}$ and $\mathrm{O}_{3}$; $E$, percent decrease in risk according to the interquartile difference $\left(3 \mu \mathrm{g} / \mathrm{m}^{3}\right)$ of $\mathrm{SO}_{2}$ in the multipollutant model according to moving average of two days (MA 2) up to 7 days (MA 7). São José dos Campos, SP, 2003-2000.
Table 3. Relative risk (RR) and respective $95 \%$ confidence interval $(95 \% \mathrm{Cl})$ for deaths due to circulatory diseases, cardiac diseases and stroke in relation to exposure to sulfur dioxide in a multipollutant model. São José dos Campos, Brazil, 2003-2007.

\begin{tabular}{|c|c|c|c|}
\hline & $\begin{array}{l}\text { Circulatory diseases } \\
\text { [RR }(95 \% \mathrm{Cl})]\end{array}$ & $\begin{array}{l}\text { Cardiac diseases } \\
\text { [RR }(95 \% \mathrm{Cl})]\end{array}$ & $\begin{array}{c}\text { Stroke } \\
{[\mathrm{RR}(95 \% \mathrm{Cl})]}\end{array}$ \\
\hline MA 2 & $1.016(0.998-1.035)$ & $1.011(0.986-1.037)$ & $1.022(0.996-1.048)$ \\
\hline MA 3 & $1.019(0.998-1.040)$ & $1.011(0.982-1.040)$ & $1.025(0.995-1.055)$ \\
\hline MA 4 & $1.025(1.003-1.048)$ & $1.020(0.990-1.052)$ & $1.027(0.995-1.059)$ \\
\hline MA 5 & $1.030(1.007-1.054)$ & $1.025(0.993-1.058)$ & $1.031(0.997-1.066)$ \\
\hline MA 6 & $1.030(1.006-1.055)$ & $1.021(0.993-1.056)$ & $1.035(1.000-1.072)$ \\
\hline MA 7 & $1.030(1.005-1.056)$ & $1.019(0.985-1.055)$ & $1.036(1.000-1.074)$ \\
\hline
\end{tabular}

$\mathrm{MA}=$ moving average. $\mathrm{P}<0.05$ for the values in bold (Poisson regression).

than a generalized additive model was based on a study conducted by Conceição et al. (17), which demonstrated that both models yield consistent results, without compromising the end result of the study. The generalized linear model was also used successfully by Arbex et al. (18) to assess the association between exposure to total suspended particles resulting from biomass burning and hospitalizations for hypertension.

The levels of pollutants reported in the present study differ from those reported for others, such as a study conducted in São Paulo, the Brazilian metropolis, which demonstrated 24-h $\mathrm{PM}_{10}$ values exceeding by several times the limit value of $150 \mu \mathrm{g} / \mathrm{m}^{3}(19)$. This finding is consistent, since São José dos Campos is a medium-sized city with a smaller vehicle fleet $(230,000$ vehicles versus 5 million in São Paulo) and industrial park, which are mainly responsible for the emission of $\mathrm{PM}_{10}(20)$. Also in São Paulo, the average $\mathrm{SO}_{2}$ value was $17.71 \mathrm{\mu g} / \mathrm{m}^{3}$, which is well above the average found in the present study $\left(4.4 \mu \mathrm{g} / \mathrm{m}^{3}\right)$, and $\mathrm{O}_{3}$ levels were close to those detected in the present study $\left(80 \mu \mathrm{g} / \mathrm{m}^{3}\right)$, with an average of $71.79 \mu \mathrm{g} / \mathrm{m}^{3}$ average (6).

Both environmental pollutants and the sum of monthly deaths throughout the study period showed markedly seasonal behavior, with increased levels of pollutants and number of deaths in the cooler times of the year (months of May, June and July) and decreased values in the warmer months of the year. This can be explained by the thermal inversion that occurs during the cold months, reducing the dispersion of air pollutants. Ozone, on the other hand, showed no seasonal pattern, since it is known that it is the result of chemical reactions involving sunlight, nitrogen oxides, and hydrocarbons derived primarily from vehicle emissions, unlike the mechanism of the other three pollutants.

The mechanisms involved in the genesis of circulatory diseases by exposure to pollutants have not been well explored, but a possible mechanism could be the increase in plasma fibrinogen and inflammatory factors, which lead 
to increased blood viscosity, resulting in clinical cardiovascular events (21).

In particular, $\mathrm{SO}_{2}$ resulting from the burning of fossil fuels is a major component of air pollution in many parts of the world. In urban areas, $\mathrm{SO}_{2}$ originates from domestic heating, power generation through thermal power plants and motor vehicles. Its inhalation is responsible for adverse health effects due to its absorption by the mucous membranes of the respiratory tract (22). A study conducted by Tunnicliffe et al. (23) using electrocardiograms suggested that exposure to $\mathrm{SO}_{2}$ can influence the autonomic nervous system, contributing to the explanation of the mechanisms involved in the cardiovascular and bronchial constriction produced by this pollutant. Another study also suggested a direct effect on the autonomic nervous system rather than effects secondary to a systemic inflammatory response, having found that short-term exposure to $\mathrm{SO}_{2}$ causes a decrease in cardiac vagal control measures (24).

In the present study, we demonstrated the association of exposure to $\mathrm{SO}_{2}$ and circulatory events that result in death. Exposure to $\mathrm{SO}_{2}$ was significantly associated with mortality due to circulatory diseases (maximum RR in the moving average of 7 days $=1.036 ; 95 \% \mathrm{Cl}=1.014-1.060$ ), after adjusting for $\mathrm{O}_{3}$. Although the $\mathrm{RR}$ estimated in this study were of low magnitude, it is important to note that exposure to air pollutants is a frequent event, resulting in a marked impact on the health system and the exposed individual.

In another study carried out in São Paulo, an increase of $10 \mu \mathrm{g} / \mathrm{m}^{3}$ in $\mathrm{SO}_{2}$ concentrations led to an $11 \%$ increase in the risk of hospital admissions due to respiratory disease, a $3 \%$ increase in hospital admissions due to cardiovascular diseases, and a $7 \%$ increase in hospital admissions due to ischemic heart disease in elderly people (18).

Along this line, Sunyer et al. (13) found in seven European regions a significant increase in the daily numbers of all cardiovascular admissions except for stroke, particularly ischemic heart disease (IHD), with an increase in the levels of $\mathrm{SO}_{2}$ in the same day and the day before. After adjustment for $\mathrm{PM}_{10}$, the combination of $\mathrm{SO}_{2}$ with IHD admissions remained significant among individuals younger than 65 years, but not among individuals older than 65 years. An increase of $10 \mu \mathrm{g} / \mathrm{m}^{3}$ of $\mathrm{SO}_{2}$ in the daily average corresponded to $0.7 \%$ of all cardiovascular hospitalizations on the same day and the next. On the other hand, a study conducted in Finland identified an association between exposure to PM and death from stroke (25)

In the present study, we chose to estimate the decrease in $\mathrm{RR}$ for a decrease in the interquartile difference in $\mathrm{SO}_{2}$ $\left(3 \mu \mathrm{g} / \mathrm{m}^{3}\right)$; under these conditions there was a decreased risk of death reaching a maximum value of approximately $8.5 \%$ in the multipollutant model. This finding reinforces the need to implement measures to decrease the concentrations of air pollutants.

This study may have limitations where the individual exposures are not considered, taking as the basis a homogeneous atmosphere throughout the analysis. Therefore, we cannot say that an individual who died was necessarily exposed to higher pollution levels. The use of the generalized linear model instead of a generalized additive model may have been another limitation, because the general additive model is a more parsimonious model that requires a smaller number of explanatory variables. Another limitation may have been a mistake in the coding of cause of death, besides the lack of information on comorbidities. The database used in this study does not identify whether the subject is a smoker or non-smoker. Another limitation was the lack of separation between deaths due to heart disease and deaths due to stroke. In our study, stroke made the most expressive contribution to the deaths recorded.

We should be careful regarding the exclusive involvement of $\mathrm{SO}_{2}$ in the occurrence of deaths because other pollutants such as $\mathrm{CO}, \mathrm{NO}$ and $\mathrm{NO}_{2}$ were not included due to the fact that they are not estimated by CETESB. It is important to note that this statistical approach and this type of study may suggest a relationship, but not necessarily a causal effect. However, it serves as a basis for the management of public health, social and financial aspects of the country.

The results of this study suggest that residents of medium-sized Brazilian cities with characteristics similar to those of São José dos Campos, which is crossed by a highway with considerable truck and bus traffic, and having a similar industrial complex, may also be affected by exposure to environmental pollutants, even when they are present in low concentrations and within the limits acceptable by environmental legislation (26).

Moreover, the death outcome examined in this study, although being the most serious, is just one of the outcomes of exposure to air pollutants, also represented by emergency consultations, hospitalizations and poorer quality of life. Thus, we observed an important role of $\mathrm{SO}_{2}$ when combined with the risk of circulatory deaths in the elderly in a Brazilian medium-sized city.

\section{Acknowledgments}

Research supported by FAPESP (\#2010/20076-3 and \#2011/06647-0). 


\section{References}

1. Brasil. Ministério da Saúde. DATASUS. Informações de Saúde. Epidemiológicas e morbidade. http://tabnet.datasus. gov.br/cgi/tabcgi.exe?sih/cnv/nrsp.def. Accessed April 24, 2012.

2. Grundy SM, Pasternak R, Greenland P, Smith S Jr, Fuster $\mathrm{V}$. Assessment of cardiovascular risk by use of multiple-riskfactor assessment equations: a statement for healthcare professionals from the American Heart Association and the American College of Cardiology. Circulation 1999; 100: 1481-1492.

3. Johnson JY, Rowe BH, Villeneuve PJ. Ecological analysis of long-term exposure to ambient air pollution and the incidence of stroke in Edmonton, Alberta, Canada. Stroke 2010; 41: 1319-1325.

4. Cançado JED, Braga A, Pereira LAA, Arbex MA, Saldiva PHN, Santos UP. Repercussões clínicas da exposição à poluição atmosférica. J Bras Pneumol 2006; 32 (Suppl 1): S5-S11.

5. Nascimento LF, Pereira LA, Braga AL, Modolo MC, Carvalho JA Jr. Effects of air pollution on children's health in a city in Southeastern Brazil. Rev Saúde Pública 2006; 40: 77-82.

6. Gouveia N, de Freitas CU, Martins LC, Marcilio IO. [Respiratory and cardiovascular hospitalizations associated with air pollution in the city of São Paulo, Brazil]. Cad Saúde Pública 2006; 22: 2669-2677.

7. Martins LC, Pereira LA, Lin CA, Santos UP, Prioli G, Luiz OC, et al. The effects of air pollution on cardiovascular diseases: lag structures. Rev Saúde Pública 2006; 40: 677-683.

8. Olmo NR, Saldiva PH, Braga AL, Lin CA, Santos UP, Pereira LA. A review of low-level air pollution and adverse effects on human health: implications for epidemiological studies and public policy. Clinics 2011; 66: 681-690.

9. Braga AL, Pereira LA, Procopio M, Andre PA, Saldiva PH. [Association between air pollution and respiratory and cardiovascular diseases in Itabira, Minas Gerais State, Brazil]. Cad Saúde Pública 2007; 23 (Suppl 4): S570-S578.

10. Cendon S, Pereira LA, Braga AL, Conceição GM, Cury JA, Romaldini $\mathrm{H}$, et al. Air pollution effects on myocardial infarction. Rev Saúde Pública 2006; 40: 414-419.

11. Nascimento LF. Air pollution and cardiovascular hospital admissions in a medium-sized city in São Paulo State, Brazil. Braz J Med Biol Res 2011; 44: 720-724.

12. Oliveira MS, Leon AP, Mattos IE, Koifman S. Differential susceptibility according to gender in the association between air pollution and mortality from respiratory diseases. Cad Saúde Pública 2011; 27: 1827-1836.

13. Sunyer J, Ballester F, Tertre AL, Atkinson R, Ayres JG, Forastiere $\mathrm{F}$, et al. The association of daily sulfur dioxide air pollution levels with hospital admissions for cardiovascular diseases in Europe (The APHEA-II study). Eur Heart J 2003; 24: $752-760$.
14. São José dos Campos. Prefeitura Municipal de São José dos Campos. http://www.sjc.sp.gov.br/acidade/populacao. asp. Accessed April 24, 2012.

15. Ferreira TM, Forti MC, Alval PC. Caracterização morfológica e química do particulado atmosférico em uma região urbana: São José dos Campos. http://mtc-m19.sid.inpe.br/ col/sid.inpe.br/mtc-m19/2011/05.26.18.34/doc/publicacao. pdf. Accessed February 27, 2012.

16. Matyasovszky I, Makra L, Bálint B, Guba Z, Sümeghy Z. Multivariate analysis of respiratory problems and their connection with meteorological parameters and the main biological and chemical air pollutants. Atmospheric Environment 2011; 45: 4152-4159.

17. Conceição GMS, Saldiva PHN, Singer JM. GLM and GAM model for analyzing the association between atmospheric pollution and morbidity-mortality markers: an introduction based on data from the city of São Paulo. Rev Bras Epidemiol 2001; 4: 206-219.

18. Arbex MA, Saldiva PH, Pereira LA, Braga AL. Impact of outdoor biomass air pollution on hypertension hospital admissions. J Epidemiol Community Health 2010; 64: 573-579.

19. Gouveia N, Mendonça GAS, Ponce-de-Leon A, Correia JEM, Junger WL, Freitas CU, et al. Poluição do ar e efeitos na saúde nas populações de duas grandes metrópoles brasileiras. Epidemiol Serv Saúde 2003; 12: 29-40.

20. São Paulo. Secretaria de Estado de Transportes. Departamento de Estradas de Rodagem do Estado de São Paulo. http://www.der.sp.gov.br/malha/estat_malha/frotaVeiculos2006.pdf. Accessed April 24, 2012.

21. Metzger KB, Tolbert PE, Klein M, Peel JL, Flanders WD, Todd $\mathrm{K}$, et al. Ambient air pollution and cardiovascular emergency department visits. Epidemiology 2004; 15: 46-56.

22. World Health Organization. WHO air quality guidelines global update. Bonn: WHO; 2005.

23. Tunnicliffe WS, Hilton MF, Harrison RM, Ayres JG. The effect of sulphur dioxide exposure on indices of heart rate variability in normal and asthmatic adults. Eur Respir J 2001; 17: 604-608.

24. Routledge HC, Manney S, Harrison RM, Ayres JG, Townend $\mathrm{JN}$. Effect of inhaled sulphur dioxide and carbon particles on heart rate variability and markers of inflammation and coagulation in human subjects. Heart 2006; 92: 220-227.

25. Kettunen J, Lanki T, Tiittanen P, Aalto PP, Koskentalo T, Kulmala $\mathrm{M}$, et al. Associations of fine and ultrafine particulate air pollution with stroke mortality in an area of low air pollution levels. Stroke 2007; 38: 918-922.

26. Brasil. Ministério do Meio Ambiente. Resolução Conama 03/1990. http://www.mma.gov.br/port/conama/legipesq.cfm ?tipo $=3 \&$ numero $=03 \&$ ano $=1990 \&$ texto $=$. Accessed October 13, 2011. 